\title{
Determination of the critical rate of hydrotransport based on measurements in supercritical flow conditions
}

\author{
Yevhen Semenenko ${ }^{1, *}$, Serhii Dziuba ${ }^{1}$, Larysa Tatarko $^{2}$, and Zinaida Yakubovska $^{2}$ \\ ${ }^{1}$ Institute of Geotechnical Mechanics named by N. Poljakov of National Academy of Sciences of \\ Ukraine, 49005, Dnipro, Simferopolska Str., 2a, Ukraine \\ ${ }^{2}$ Ukrainian State University of Chemical Technology, 49600, Dnipro, Haharina Ave., 8, Ukraine
}

\begin{abstract}
The article solves the actual problem of determining the value of the critical rate of hydrotransport for a specific hydrotransport unit in terms of its operation in supercritical flow conditions, without violating the process regulations and the required freight traffic for processing. Based on the analysis and generalization of the known methods of calculating the parameters of hydrotransport, a methodical approach was proposed for determining the value of the critical rate of hydrotransportation according to the dependence of the hydraulic slope on the speed and concentration of the slurry. The efficiency of the developed methodology was proved based on the results of measurements of the parameters of the Vilnohirsk State Mining and Metallurgical Plant hydrotransport complex in supercritical conditions. The reliability of the developed technique is confirmed by the fact that the relative error in determining the critical rate of hydrotransport according to the methods improved by the author does not exceed $7 \%$, and in determining the hydraulic slope does not exceed $6 \%$, respectively.
\end{abstract}

\section{Introduction}

All domestic mining and processing and mining and metallurgical plants, coal preparation and ore-concentration plants, as well as enterprises for processing technogenic deposits, use pipeline transport with pump sin their technological cycle [1-3].With the rising cost of electricity and industrial water there is a need to improve the efficiency of this type of transport, due to ensuring the profitability of concentrates of finished products. In this situation, the desire of some enterprises to increase the concentration of transported slurry or reduce the power of the pumping units in operation hassled to a decrease in the reliability of the hydraulic transport process and to emergency situations caused by the occurrence of critical pulp flow regimes followed by silting of pipelines and shutdowns of then tire production process. In both cases, a decrease in the actual flow rate below the critical rate of hydraulic transport was observed [1, 4].

The magnitude of the critical rate of hydraulic transport depends on the ratio of the parameters of the pipeline, the transported material and the carrier phase of the slurry, and,

*Corresponding author: evs_post@meta.ua 
as a rule, is calculated when designing the hydraulic transport unit. According to the value of the critical rate of hydraulic transport and the required performance of the hydraulic transport unit, the diameter of the pipeline is determined by slurry, which is rarely changed during operation.

Initially, the critical rate of hydraulic transport was determined exclusively experimentally by fixing the moment of precipitation of particles of the solid phase from the stream to the bottom of the pipeline. For this purpose, special stands were used in pipelines, which could change the flow rate. This ensured the implementation of the critical regime, with the subsequent formation of the silting body, and a non-stop transition to the supercritical flow, followed by the erosion of the silting body. The results of these experiments allowed us to construct the dependence of the critical rate of hydraulic transport on the concentration of the slurry [1-3]. Subsequently, calculation methods for determining the critical rate of hydraulic transport have appeared which did not require experimental studies [1-3].However, after the hydraulic transport unit was put into operation, none of the manufacturers was interested in the value of the critical rate of hydrotransport. All measuring devices were focused on measuring the actual speed and flow rate of the slurry, the concentration of the solid phase and cargo flow, as well as the pressure of the slurry at different points of the line, which allows us to determine the hydraulic slope of the line and the energy intensity of the hydrotransportation process [1 - 4].

The interest of manufacturers and designers to the magnitude of the critical rate of hydrotransportion for the conditions of existing hydrotransport installations appeared in connection with:

- the appearance of more advanced mining pumps at mining and processing plants than foreign-made pumps in the former USSR, which allow transporting more dense slurry over long distances with smaller dimensions and a smaller unit weight;

- the significant lengthening of lines, which required the use of several seriesconnected pumps;

- the need to periodically lengthen the lines in connection with the advancement of the mining front and the removal of storage sites for enrichment waste;

- the significant fluctuations in the parameters of the transported material, due to the complex mining and geological conditions of the deposits;

- the usage of hydrotransportation pipes made from polymeric materials.

Nowadays there is no such possibility to experimentally determine the magnitude of the critical speed in laboratory conditions while the conduct of industrial experiments is not possible, since the onset of the critical mode would mean stopping the entire enterprise. Meanwhile about 20 methods for calculating the critical speed and hydraulic slope during pulp flow, known in the former USSR [1,2], do not take into account a number of features of primary and legacy placers, such as the presence of particles of significantly different density in polydisperse material [1 - 4].Thus, the goal of determining the value of the critical rate of hydrotransport for a specific hydrotransportation unit in terms of its operation in supercritical flow regimes, without violating the process regulations and the required freight for concentrating production has become of much importance.

\section{Methods}

The systems of monitoring the parameters and modes of operation of hydrotransport complexes used at domestic enterprises involve the measurement of flow, density and concentration of the slurry, as well as the flow pressure in the suction and discharge nozzles of the pumps used. All these parameters are due to the operating point of the system, which is determined by the intersection of the flow-pressure characteristics of the line and pumps used $[1-4]$ : 


$$
H_{\mathrm{M}}=k_{\mathrm{L}} i L+\rho_{\mathrm{c}} \Delta Z ; H=\left(\gamma-\beta Q-\alpha Q^{2}\right)\left(1+\frac{S^{1.2}}{\sqrt{\psi}}\right) ; \rho_{\mathrm{c}}=1+A r_{\mathrm{c}} S_{\mathrm{c}} ; \psi=\frac{\omega}{\sqrt{g d}},
$$

where $H_{\mathrm{M}}$ - flow characteristics of the line; $i$-hydraulic slurry slope; $k_{\mathrm{L}}$ - coefficient taking into account the influence of local hydraulic resistance; $L$ - pipeline length; $\rho_{c}-$ carrier fluid density; $S_{\mathrm{c}}$ - carrier fluid concentration; $\Delta Z$ - difference of geodetic altitude of the pipeline; $H$ - pressure head developed by slurry; $\gamma, \beta, \alpha$ - approximation coefficients of the passport flow-pressure characteristics of the pump; $Q$ - pump output; $\psi-$ coefficient of transportability of particles of solid material (Table 1) [1]; $\omega-$ hydraulic size of solid particles; $d$-average particle size; $g$ - free fall acceleration, $S-$ slurry concentration.

Table 1. Formulas for determining the value for particles of different fractions.

\begin{tabular}{|c|c|c|}
\hline Fractions & Particle diameter & Formula for calculating $\psi$ \\
\hline Fine fractions & Up to $0.15 \mathrm{~mm}$ & $\psi=2778 \sqrt{g d^{3}} A r$ \\
\hline Small fractions & from 0.15 to $3 \mathrm{~mm}$ & $\psi=\left(a \sqrt{d}-\frac{b}{\sqrt{d}}\right) A r$ \\
\hline Lump fractions & More than $3 \mathrm{~mm}$ & $\psi=1.67 \sqrt{A r}$ \\
\hline
\end{tabular}

Note: $a, b$ are coefficients depending on temperature [1].

However, none of the components in the equation (1) does not depend explicitly on the critical rate of hydrotransport. In order to solve the problem we have analyzed more than 20 well-known in the former USSR methods of calculating the parameters of hydrotransport designed by such authors as Yufin, Traynis, Smoldyrev, Dmitriev, Silin - Kobernik, Asaulenko, Kobernik - Voitenko, Karasik, Nurok - Grishko, Aksenov - Podkorytova, Zhivotovsky - Khalsenberg as well as the research papers of specialized technological institutes in Moscow [1 - 4]. The analysis of the dependence of hydraulic slope on the speed and concentration of the slurry, as well as the dependence of the critical speed on the concentration of the slurry and the properties of the transported material, shows that the dependence of the hydraulic slope on the critical rate of hydrotransport is expressed through the parameter of hydrotransport calculated as the ratio of the actual speed to the critical speed:

$$
i=b_{0}\left(1+\frac{b_{1}}{k_{\mathrm{v}}^{m}}\right) i_{0} ; i_{0}=\frac{\lambda}{2} F r^{2} ; k_{\mathrm{V}}=\frac{F r}{F r_{\mathrm{cr}}} ; F r=\frac{V}{\sqrt{g D}} ; F r_{\mathrm{cr}}=\frac{V_{\mathrm{cr}}}{\sqrt{g D}},
$$

where $k_{\mathrm{V}}$ - the parameter of hydrotransport; $b_{0}, b_{1}$ - the coefficients of dependence of hydraulic slope on the parameter of hydrotransportation (Table 2); $m$ - the power exponent in the dependence of the hydraulic slope on the parameter of hydrotransport (Table 2); $\lambda-$ the pipe friction drag number; $F r$ - the actual value of the Froude number; $F r_{\text {cr }}-$ the critical value of the Froude number (Table 3); $V$ - the average discharge velocity of slurry; $V_{\text {cr }}$ - hydrotransportation critical velocity; $g$ - the free fall acceleration; $D$ - pipeline diameter; $i_{0}$ - hydraulic slope to the flow of carrier fluid. 
Table 2. The parameters of the dependence of the hydraulic slope on the mode of hydrotransport.

\begin{tabular}{|c|c|c|c|}
\hline \multirow{2}{*}{ Method created by } & \multirow{2}{*}{$\begin{array}{c}\text { Value of } \\
\quad m\end{array}$} & \multicolumn{2}{|c|}{ Formulas for calculation } \\
\hline & & $b_{0}$ & $b_{1}$ \\
\hline Nurok - Grishko & $2+n$ & $1+A r S_{\mathrm{c}}$ & $2\left(k \frac{A r\left(1-S_{c}\right)}{1+A r S_{c}}\right)^{0.5(1-n)} S^{-0.25 n}$ \\
\hline $\begin{array}{l}\text { VNIIzhelezobeton and } \\
\text { Proecthydromekhanizatsia }\end{array}$ & 2.8 & 1 & 0.003 \\
\hline Traynis & 3 & $1+A r S$ & $\frac{1.99}{\psi} \sqrt{\frac{\lambda}{c}} \sqrt{\frac{1+A r S}{S}}$ \\
\hline Aksenov - Podkorytova & 3 & 1 & $0.12 \delta^{0.834}$ \\
\hline Yufin & 2.35 & $1+A r S$ & $(3.5+2 D+0.5 \sqrt{d})(A r S)^{0.8}$ \\
\hline Duran & 3 & 1 & 1 \\
\hline Zhivotovsky - Khalsenberg & 2.8 & 1 & 1 \\
\hline Silin - Kobernik & 3 & $1+0.5 S$ & 1 \\
\hline Asaulenko & 1 & $\frac{\lambda-S}{\lambda(1+A r S)^{-1}}$ & 1 \\
\hline Kobernik - Voitenko & 3 & $1+S_{\mathrm{c}} A r S$ & $\frac{\lambda_{\mathrm{kp}}}{\lambda}\left(\frac{1+150 \delta}{1+S A r S_{\mathrm{c}}}(1+A r S)^{1.5}-1\right.$ \\
\hline Karasik & 1 & $\frac{2 \sqrt{S}-1}{\sqrt{S}}$ & $\frac{0.7}{2 \sqrt{S-1}}$ \\
\hline Dmitriev(Smallfractions) & 3 & 1 & $2 c_{1}\left(\lambda c^{3}\right)^{-1}$ \\
\hline Dmitriev(Lumpfractions) & 2 & 1 & $2\left(\lambda c^{2}\right)^{-1}$ \\
\hline $\begin{array}{c}\text { Smoldyrev } \\
\text { (Smallfractionsof ore) }\end{array}$ & 4 & $1+\frac{A r\left(1-S_{\mathrm{c}}\right) S}{1+A r S_{\mathrm{c}}}$ & $\frac{2 c_{0}}{\lambda c^{4}}$ \\
\hline Smoldyrev(Smallfractions) & 3 & 1 & $2 c_{1} g\left(\lambda c^{3}\right)^{-1}$ \\
\hline Smoldyrev(Lumpfractions) & 2 & 1 & $2\left(\lambda c^{2}\right)^{-1}$ \\
\hline
\end{tabular}

In the Table 2: $A r$ - the parameter of Archimedean solids; $\delta$ - the relative diameter of solid particles; $n, k$ - the trial coefficients; $c_{1}$ - the trial coefficient for fine particles of coal; $c$ - the trial coefficient for lump particles of coal; $c_{0}$ - the trial coefficient for fine particles of ore; $\lambda_{\text {cr }}$ - the coefficient of hydraulic friction resistance in a critical mode; $f$ the generalized friction coefficient of coarse fraction particles on pipe lower wall.

Note. In the Tables 1 and 2 such values are used: 


$$
A r=\frac{\rho_{\mathrm{S}}-\rho_{\mathrm{w}}}{\rho_{\mathrm{w}}} ; \quad \delta=\frac{d}{D},
$$

where $\rho_{\mathrm{S}}$ - the solid particle density; $\rho_{\mathrm{w}}$ - density of water.

Table 3. Characteristics of the dependence of the critical velocity on the properties of the material.

\begin{tabular}{|c|c|c|c|c|c|}
\hline \multirow{2}{*}{ Method created by } & \multicolumn{4}{|c|}{ Power exponent } & \multirow{2}{*}{ Formula for $F r_{\text {cr }}$} \\
\hline & $\psi$ & $\delta$ & $A r$ & $S$ & \\
\hline Nurok - Grishko & 0 & 0 & $1 / 2$ & $1 / 4$ & $\sqrt{k \frac{A r\left(1-S_{\mathrm{c}}\right)}{1+A r S_{\mathrm{c}}} S^{0.5}}$ \\
\hline $\begin{array}{l}\text { VNIIzhelezobetonand } \\
\text { Proecthydromechanizatia }\end{array}$ & $1 / 3$ & 0 & 0 & 0,36 & $48.99 \sqrt[3]{\psi} S^{0.36}$ \\
\hline Traynis & 1 & 0 & 0 & $1 / 2$ & $\psi \sqrt{c S \lambda^{-1}(1+A r S)^{-1}}$ \\
\hline Aksenov - Podkorytova & $2 / 3$ & $1 / 6$ & $1 / 6$ & $1 / 6$ & $1.241 \sqrt[6]{\delta A r S} \psi^{2 / 3} \lambda^{-1 / 3}$ \\
\hline Yufin & $1 / 4$ & $1 / 8$ & 1 & 1 & $\frac{9.8(A r S+0.6)}{\sqrt[24]{g^{9} D^{7}}} \sqrt[4]{\psi^{8} \sqrt[8]{\delta}}$ \\
\hline Duran & $1 / 2$ & $1 / 4$ & 0 & $1 / 3$ & $5.749 \sqrt[3]{S} \sqrt{\psi} \sqrt[4]{\delta}$ \\
\hline Zhivotovsky - Khalsenberg & $1 / 2$ & 0 & $-1 / 4$ & 0,36 & $5.764 S^{0,36} \sqrt{\psi} A r^{-1 / 4}$ \\
\hline Silin - Kobernik & 0 & 0 & 0 & $1 / 3$ & $\sqrt[3]{\frac{36.93 S}{1+0.5 S}}$ \\
\hline Asaulenko & 1 & $1 / 2$ & 1 & 1 & $\frac{\lambda A r S \psi \sqrt{\delta}}{(\lambda-S)(1+A r S)}$ \\
\hline Kobernik - Voitenko & $1 / 4$ & $1 / 8$ & 1 & 1 & $\frac{15(A r S+0.6)}{\sqrt[24]{g^{9} D^{7}}} \sqrt[4]{\psi^{8} \sqrt[8]{\delta}}$ \\
\hline Karasik & $1 / 3$ & $1 / 6$ & $1 / 2$ & $1 / 6$ & $7.56 \sqrt[3]{\psi} \sqrt{A r} \sqrt[6]{S \delta}$ \\
\hline Dmitriev (Small fractions) & $1 / 3$ & $1 / 6$ & $1 / 3$ & $1 / 3$ & $c \sqrt[3]{\operatorname{ArS} \psi} \sqrt[6]{\delta}^{-}$ \\
\hline Dmitriev (Lump fractions) & 1 & 0 & 0 & $1 / 2$ & $0.6 c \psi \sqrt{f S}$ \\
\hline $\begin{array}{c}\text { Smoldyrev } \\
\text { (Smallfractions of ore) }\end{array}$ & $1 / 2$ & 0 & $1 / 4$ & $1 / 4$ & $c_{0} \sqrt{\psi} \sqrt{\operatorname{ArS} S(1+\operatorname{ArS})^{-1}}$ \\
\hline $\begin{array}{c}\text { Smoldyrev } \\
\text { (Small fractions of coal) }\end{array}$ & $1 / 3$ & 0 & $1 / 3$ & $1 / 3$ & $c_{1} \sqrt[3]{A r S \psi g^{-1}}$ \\
\hline Smoldyrev (Lump fractions) & 1 & 0 & 0 & $1 / 2$ & $0.6 c \psi \sqrt{f S}$ \\
\hline
\end{tabular}

Table 1 shows that the value of the coefficient is almost equal to the dimensionless density of the carrier fluid, and therefore it is determined by the density of fine particles and their mass fraction. The value of the coefficient depends on the concentration of the slurry, the particles density, and in some cases on the ratio of the diameters of the particles and the pipeline, which can be explained by the experimental conditions of study.

The equations (2) together with the formulas from Table 2 allow us to determine the critical value of the Froude number based on the results of measurements of the parameters 
of the hydrotransport installation in supercritical conditions for any of the considered calculation methods.

$$
F r_{\mathrm{cr}}^{*}=\sqrt[m]{\frac{i-b_{0} i_{0}}{b_{1} b_{0} i_{0}}} F r
$$

where $F r_{\text {cr }}^{*}$ - the critical value of the Froude number, resulted from measurements in industrial conditions.

In this case, the value is calculated from the readings of pressure gauges or differential pressure gauges on the horizontal section of the pipeline, and the values $i_{0}, b_{0}$ and $b_{1}$ are determined by equations (2) and Table 2 . Then, on correlating the values obtained by the equation (3) with the values get from the formulas in the Table 3, we get the correction factor:

$$
r=\frac{F r_{\mathrm{cr}}}{F r_{\mathrm{cr}}^{*}}
$$

In order to test the proposed methodology for determining the critical rate of hydrotransport based on measurements in supercritical flow conditions, we have used the data from the Vilnohirsk State Mining and Metallurgical Plant hydrotransport complex monitoring system, developed and implemented with the participation of the authors in 2005-2009 [1, 3-5].

\section{Results and discussion}

The Vilnogorsk State Mining and Metallurgical Plant hydrotransport complex processes the alluvial deposit of the Eastern section of the Malyshevsky occurrence in Ukraine (Fig. 1 and 2, Tables 4 and 5).

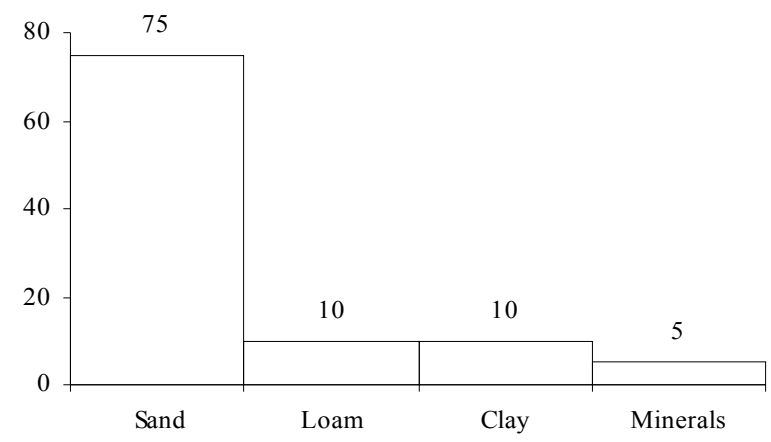

Fig. 1. Fractional composition of the alluvial deposit of the Eastern section of the Malyshevsky occurrence $[1,3]$.

The development is conducted by the quarries 7 North and 7 South that are divided one from another by a field barrier [1, 3 - 5].The delivery of the initial sands from the quarries to the enrichment production is carried out in two phases of the hydrotransport complex, first one ensures the supply of alluvial deposits from the 7 North open pit, and the other from the 7 South open pit. 


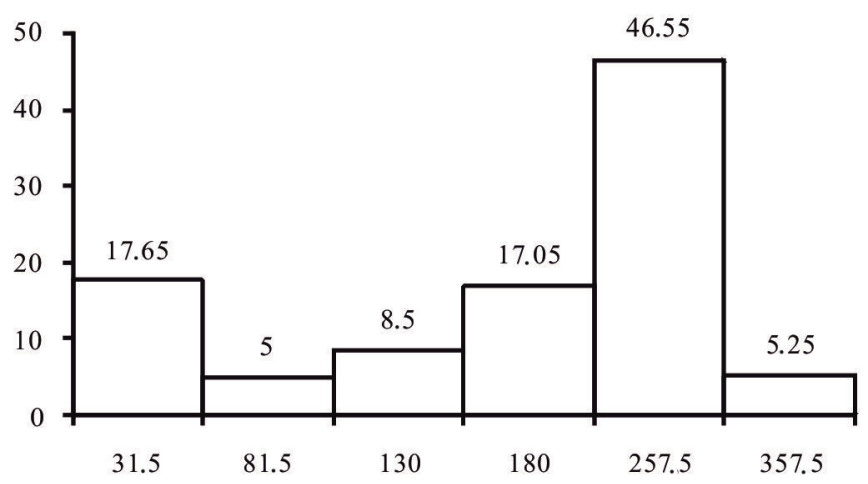

Fig. 2. Grain size distribution of the alluvial deposit of the Eastern section of the Malyshevsky occurrence $[1,3]$.

Table 4. The density of the materials included in the mixture of the Eastern section of the Malyshevsky occurrence $[1,3]$.

\begin{tabular}{|l|c|c|c|c|}
\hline \multirow{2}{*}{ Characteristic } & \multicolumn{4}{|c|}{ Material } \\
\cline { 2 - 5 } & Loam & Clay & Sand & Minerals \\
\hline Density, $\mathrm{kg} / \mathrm{m}^{3}$ & 2720 & 2750 & 2700 & 4590 \\
\hline Content in mixture, \% & 10.00 & 10.00 & 74.69 & 5.31 \\
\hline
\end{tabular}

Table 5. Grain size distribution of the materials of the alluvial deposit of the Eastern section of the Malyshevsky occurrence [1,3].

\begin{tabular}{|c|c|c|c|c|}
\hline \multirow{2}{*}{ Grain-size category, $\mu \mathrm{m}$} & \multicolumn{4}{|c|}{ Material content in mixture, \% } \\
\cline { 2 - 5 } & Sand & Loam & Clay & Minerals \\
\hline Less than 63 & 0 & 90 & 75 & 23 \\
\hline from 63 to 100 & 1 & 6 & 10 & 53 \\
\hline from 100 to 160 & 8 & 3 & 13 & 18 \\
\hline from 160 to 200 & 22 & 1 & 2 & 5 \\
\hline from 200 to 315 & 62 & 0 & 0 & 1 \\
\hline from 315 to 400 & 6 & 0 & 0 & 0 \\
\hline from 400 to 3000 & 1 & 0 & 0 & 0 \\
\hline
\end{tabular}

The pipelines can be divided into two parts, one of which runs from the processing plant to the pit walls, and the second runs along the inter-ore section of the 7 North and 7 South quarries to the current face position [1, 3 - 5].The first part is characterized by a significant difference in the geodetic marks of the beginning and end of the pipeline and in the plan it appears as a broken line. The second part of the line, located within the Eastern section of the Malyshevsky occurrence, is a long straight horizontal pipeline that runs along a geodetic elevation of $130 \mathrm{~m}$ above sea level through the Baltic system of heights.

The head pumping station is located in the bottom hole and periodically moves after the mining front at $390 \mathrm{~m}$. Pipelines of the hydrotransport complex are mounted from steel pipes with a diameter of $606 \mathrm{~mm}$ with a section length of $6 \mathrm{~m}$ and a polyethylene pipe PE 80 SDR 21 with a diameter of $630 \mathrm{~mm}$ with a wall thickness of $30 \mathrm{~mm}$. The discharge flow of the slurry through the pipelines of the Vilnohirsk State Mining and Metallurgical Plant 
hydrotransport complex is carried out according to the "pump-to-pump" scheme. Until the year of 2000, two GRT4000 centrifugal pumps were used, then GIW WBC 18 x 20 and WARMAN pumps were introduced into this process equipped by the impellers with diameters of 49, 50, 52 and 54 inches. All of the pumping units are equipped with $1600 \mathrm{~kW}$ synchronous electric motors with a rotor speed of $500 \mathrm{rpm}$.

In order to study the parameters and modes of the process of hydrotransport in the conditions of the hydroelectric transport complex of the Vilnohirsk State Mining and Metallurgical Plant, with the participation of the authors in 2005-2009, a monitoring system for the hydrotransport complex was developed and implemented [1,3]. The notion of monitoring the hydrotransport system includes a set of measures aimed to collect, register, process, analyze and summarize information on the parameters and modes of operation of the hydrotransport system in order to create a database to evaluate the operating efficiency and justify the initial data for calculations [1, 3]. Measurement data carried out during the monitoring process was summarized in the form of a Passport of a hydrotransport complex containing information at the time of its completion on the hydrotransport scheme, parameters and characteristics of installed pumping equipment, valves and pipelines, as well as on averaged performance of the hydrotransport complex in regulated operating modes, when working on water, with a load of 500, 1000 and $1200 \mathrm{t} / \mathrm{hr}$.

In the process of the monitoring we have applied the existing on-line monitoring system of the Vilnohirsk State Mining and Metallurgical Plant hydrotransport complex based on the analog-to-digital coder Nudam I $70712 \times \mathrm{CPU} 600 \mathrm{MHz} 20 \mathrm{MB}$ SCI, equipped with measuring and recording devices, as well as the corresponding computer software. The measurements of the slurry pressure in the suction and discharge nozzles of the pumps were carried out with the help of SHETRAI-43 gauges, equipped with a UKKP-8 indicating instrument. The density of slurry was measured with Bertkold LB 367 density meter. The efficiency of the hydrotransport complex for ore was calculated as the difference between the capacity of the slurry and the consumption of the circulating water. The consumption of slurry was measured directly after the head pumping stations with a UDR-010 flow meter and the flow of circulating water was measured before ingress to the pulping unit with a UVR-010 flow meter. The volumes of electricity consumed were recorded with standard measuring tools of the ore mine, and the total monthly values were provided by the energy service of the mine in accordance with the existing reporting.

According to the results of monthly tests, the average performance of the Vilnohirsk State Mining and Metallurgical Plant hydrotransport complex was determined: sand ingress per month (t), pulping time per month (hr), hourly productivity $(\mathrm{t} / \mathrm{hr})$, electric power consumption per month $(\mathrm{kW} \cdot \mathrm{hr})$, hydrotransport energy capacity $(\mathrm{kW} \cdot \mathrm{hr} / \mathrm{t})$, circulating water consumption per month $\left(\mathrm{m}^{3}\right)$, specific circulating water charge $\left(\mathrm{m}^{3} / \mathrm{t}\right)$, operating time on water per month (hr). Due to the testing the operating modes of the hydrotransport complex before and after the installation of the polyethylene pipe section, as well as the data of monthly reports on the hydrotransport section, it was made possible to evaluate the hydraulic slope in steel and polyethylene pipes (Tables 6, 7).

When carrying out the calculations the internal diameter of steel pipes was taken to be $0.6 \mathrm{~m}$, polyethylene pipe $-0.57 \mathrm{~m}$, weighted average density and size of the transported material $-2802 \mathrm{~kg} / \mathrm{m}^{3}$ and $0.19 \mathrm{~mm}$ respectively, mass fraction of particles with a particle size of less than and more than $0.1 \mathrm{~mm}-0.314$ and 0.686 unit fractions respectively, and the hydraulic particle size of solid particles $-0.0157 \mathrm{~m} / \mathrm{s}$.

Taking into account the previously obtained results, the tables 1 - 3 and equation (3) for the methods of Yufin and Kobernik-Voitenko, the following two formulas came up in a result for calculating the experimental values of the critical rate of hydrotransport: 


$$
\begin{aligned}
& V_{c r}=\sqrt[3]{\left(\frac{i}{i_{0}}-1\right) \frac{1}{q \sigma} V}, \\
& V_{c r}=V\left[\left(\frac{i}{i_{0}}-1\right) \frac{1}{\sigma}\right]^{0.373}, \quad q=\frac{\lambda}{\lambda^{\prime}},
\end{aligned}
$$

where $\sigma$ - empirical coefficient taking into account the change in the coefficient of friction of lumpy particles on the bottom of the pipe; $\lambda^{\prime}-$ the coefficient of hydraulic resistance of friction in polyethylene pipes; $\lambda-$ the coefficient of hydraulic resistance of friction in steel pipes.

Table 6. The averaged data of measurements of the hydraulic slope of the main line of the Vilnohirsk State Mining and Metallurgical Plant hydrotransport complex at a constant density of the transported material

\begin{tabular}{|c|c|c|c|c|c|}
\hline \multicolumn{2}{|c|}{ Parameters of Slurry } & \multicolumn{2}{c|}{ Supply, $\mathrm{m}^{3} / \mathrm{hr}$} & \multicolumn{2}{c|}{ Hydraulic slope in pipes } \\
\hline Concentration & Density & Pulp & Water & Steel+polyethylene & Steel \\
\hline 0.1085 & 1.196 & 2699 & 2406 & 0.0119 & 0.0142 \\
\hline 0.1981 & 1.357 & 2754 & 2208 & 0.0142 & 0.0165 \\
\hline 0.2138 & 1.385 & 2705 & 2127 & 0.0132 & 0.0152 \\
\hline 0.2255 & 1.406 & 2738 & 2120 & 0.0126 & 0.0149 \\
\hline
\end{tabular}

Table 7. The averaged data of measurements of the hydraulic slope of the main line of the Vilnohirsk State Mining and Metallurgical Plant hydrotransport complex at the different density of the transported alluvial deposit

\begin{tabular}{|c|c|c|c|c|c|c|}
\hline \multirow{2}{*}{ Concentration } & \multicolumn{2}{|c|}{ Density } & \multicolumn{2}{c|}{ Supply, $\mathrm{m}^{3} / \mathrm{hr}$} & \multicolumn{2}{c|}{ Hydraulic slope in pipes } \\
\cline { 2 - 7 } & $\begin{array}{c}\text { Alluvial } \\
\text { deposit }\end{array}$ & Pulp & Pulp & Water & Steel+polyethylene & Steel \\
\hline 0.196 & 2.697 & 1.332 & 2526 & 2030 & 0.0156 & 0.0172 \\
\hline 0.206 & 2.880 & 1.388 & 2544 & 2019 & 0.0160 & 0.0173 \\
\hline 0.201 & 3.007 & 1.403 & 2535 & 2026 & 0.0152 & 0.0168 \\
\hline 0.192 & 3.285 & 1.438 & 2502 & 2022 & 0.0176 & 0.0196 \\
\hline 0.205 & 3.439 & 1.500 & 2390 & 1901 & 0.0164 & 0.0182 \\
\hline 0.185 & 3.607 & 1.482 & 2421 & 1974 & 0.0172 & 0.0188 \\
\hline
\end{tabular}

The results of the research at the Vilnohirsk State Mining and Metallurgical Plant hydrotransport complex (Table 6,7), in the form of the results of calculations using equations (5) and (6), were compared with the results of calculations based on the generalized dependence of Institute of Geotechnical Mechanics named by N. Poljakov of National Academy of Sciences of Ukraine (Fig. 3, Table 8) [6, 7]:

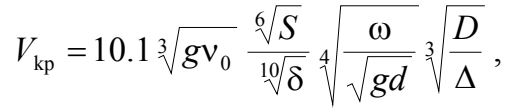

And according to A. Smoldyrev's calculations from Table 3 (Table 8).

Taking into account the data from Figure 3, Table 7 and Table 8, it follows that the results of calculations for the proposed dependence are in satisfactory agreement with the results of 
experiments.

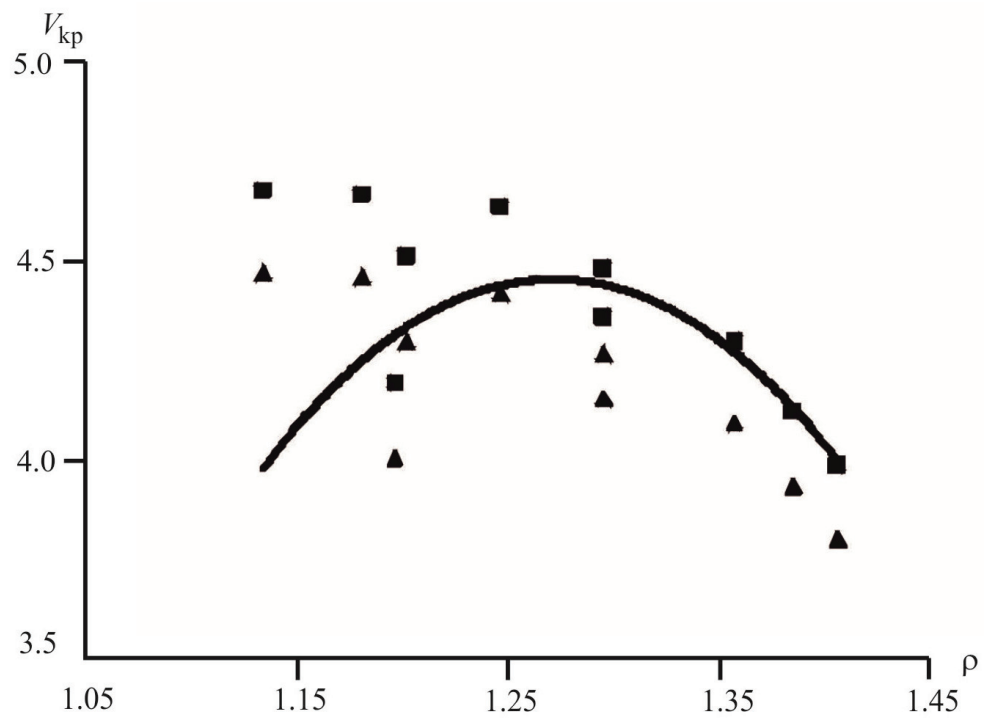

Fig. 3. Comparison of the values of the critical rate of hydrotransport, obtained in the course of the research, with theoretical values for the primary sands of the Vilnohirsk State Mining and Metallurgical Plant hydrotransport complex quarries in polyethylene pipes: - - equation (5); equation (6); - - method of Institute of Geotechnical Mechanics equation (7).

Table 8. Comparison of the results of theoretical calculations of the critical rate of hydrotransport of the primary sands at the Vilnohirsk State Mining and Metallurgical Plant hydrotransport complex quarries through polyethylene pipes with the data of industrial experiments.

\begin{tabular}{|c|c|c|c|c|}
\hline \multirow{2}{*}{ Relative density of slurry } & \multicolumn{3}{|c|}{ The ratio of the value calculated by the equations } \\
\cline { 2 - 5 } & \multicolumn{2}{|c|}{ Equation (7) and } & \multicolumn{2}{c|}{ Author's (Table 3) and } \\
\cline { 2 - 5 } & Equation (5) & Equation (6) & Equation (5) & Equation (6) \\
\hline 1.196 & 1.199 & 1.144 & 0.975 & 0.930 \\
\hline 1.357 & 1.258 & 1.201 & 1.023 & 0.976 \\
\hline 1.385 & 1.231 & 1.175 & 1.001 & 0.955 \\
\hline 1.406 & 1.205 & 1.150 & 0.980 & 0.936 \\
\hline 1.134 & 1.448 & 1.382 & 1.177 & 1.124 \\
\hline 1.181 & 1.359 & 1.297 & 1.105 & 1.055 \\
\hline 1.202 & 1.276 & 1.218 & 1.038 & 0.991 \\
\hline 1.246 & 1.244 & 1.188 & 1.012 & 0.966 \\
\hline 1.295 & 1.217 & 1.162 & 0.990 & 0.945 \\
\hline 1.295 & 1.252 & 1.195 & 1.018 & 0.972 \\
\hline & 1.269 & 1.211 & 1.032 & 0.985 \\
\hline Averagevalue & 0.055 & 0.053 & 0.045 & 0.043 \\
\hline Standarddeviation & 4.35 & 4.35 & 4.35 & 4.35 \\
\hline Coefficient of variation, \% & & & & \\
\hline
\end{tabular}

In this case, the relative error of the average values is 3.07 and $1.62 \%$, respectively, for equations (5) and (6), and the maximum relative deviation does not prevail 4 and $7 \%$. 


\section{Conclusions}

Based on the analysis and generalization of the known methods of calculating the parameters of hydrotransport, as a result the methodical approach was proposed for determining the value of the critical rate of hydrotransportation according to the dependence of the hydraulic slope on the speed and concentration of the slurry. The working efficiency of the developed methodology was proved based on the results of measurements of the parameters of the Vilnohirsk State Mining and Metallurgical Plant hydrotransport complex in supercritical conditions.

The reliability of the developed method is proved by the fact that the relative error in determining the critical rate of hydrotransport according to the method developed by S.Kobernik - V.Voitenko and A. Smoldyrev does not exceed $7 \%$ and $18 \%$, respectively. Neither does it exceed $6 \%$ and $7 \%$, respectively when determining the hydraulic slope.

Thus we have solved the actual problem of determining the value of the critical rate of hydrotransport for a specific hydrotransport unit according to its performance in supercritical flow regimes, without violating the process regulations and the required freight traffic for the enrichment production.

\section{References}

1. Semenenko, Ye.V. (2011). Nauchnyie osnovyi tehnologiy gidromehanizatsii otkryitoy razrabotki titan-tsirkonovyih rossyipey. Kiev: Naukova dumka

2. Baranov, Yu.D., Blyuss, B.A., Semenenko, Ye.V., Shuryigin, V.D. (2006). Obosnovanie parametrov $i$ rezhimov rabotyi sistem gidrotransporta gornyih predpriyatiy. Dnepropetrovsk: Novaya ideologiya

3. Maharadze, L.I., Gochitashvili, T.Sh., Kril, S.I., Smoylovskaya, L.A. (2006). Truboprovodnyiy gidrotransport tverdyih syipuchih materialov. Tbilisi: Metsniereba

4. Shuryigin, V.D., Semenenko, Ye.V., Nikiforova, N.A. (2005). Analysis of ways to improve the efficiency of the hydrotransport complex, Metallurgicheskaya $i$ gornorudnaya promyishlennost [Metallurgical and Mining Industry], 6, 70 - 74

5. Shuryigin, V.D., Semenenko, Ye.V. (2007). Calculation of parameters of the hydrotransport complex using polyethylene pipes, Metallurgicheskaya i gornorudnaya promyishlennost [Metallurgical and Mining Industry], 2, $71-74$

6. Semenenko, Ye., Nykyforova, N., Tatarko, L. (2015). The features of calculations of hydrotransport plans of geotechnological systems. Theoretical and practical solutions of mineral resources mining, $397-401$

7. Semenenko, Ye., Nykyforova, N. Tatarko, L. (2015). An improved procedure of hydrotransport parameters' calculation for flows in polyethylene pipes and with friction reducing agents. In: XVII International Conference Transport and Sedimentation of solid particles, September, $300-308$ 